\title{
Analysis on the Current Situation and Countermeasures of Domestic Agricultural Marketing
}

\author{
Xiuping Liu ${ }^{1, a}$, Yuan Qian ${ }^{1, b}$, Lei Zhou ${ }^{1, c}$ \\ ${ }^{1}$ Nanchang Institute of Science \& Technology, Nanchang, Jiangxi, 330000 \\ ${ }^{a}$ email, ${ }^{b}$ email, ${ }^{c}$ email
}

Keywords: Current Situation, Countermeasures of Domestics Agricultural Marketing

\begin{abstract}
With the arrival of the relatively surplus of agricultural products to determine the market as the center of modern agricultural marketing concept is particularly urgent. Agricultural product marketing is to meet people's consumer needs and desire to achieve the potential exchange of agricultural activities of the process. Agricultural marketing requires agricultural producers not only to study the real needs of people, but also to study the potential demand for agricultural products and create demand. To take into account the production, transmission and eventually exchange all the elements of agricultural links, co-ordination arrangements to meet customer needs, in order to achieve the profit target of agricultural marketers.
\end{abstract}

\section{Introduction}

Reform and opening up, especially since the accession to the WTO, China's agricultural marketing began to flourish. The agricultural market system has been initially established and developed rapidly. Over the past 20 years, China's agricultural products wholesale market from scratch, from small to large, now has a considerable scale, the number of 4300 or so, the annual turnover of more than 700 billion yuan, of which more than 599 million yuan. Large and medium-sized cities more than $80 \%$ of the fresh agricultural products through the agricultural products wholesale market, the wholesale market has become the main channel for agricultural products circulation. China's agricultural products market has experienced more than 10 years of rapid growth and scale expansion, is now gradually from the number of expansion to improve the quality of the change, the scale of the flow on the steps, the market hardware facilities improved significantly, increasing the grade of goods, market operation The quality is getting better.

The establishment of a more complete domestic agricultural products wholesale market. At present, the main channel of agricultural products is the wholesale market of agricultural products. At present, large, medium and small cities consumption of fresh agricultural products $80 \%$ to $90 \%$ is provided through the wholesale market. In recent years, with the economic development, / agricultural reform has become a trend. Many farmers market has gradually changed the form of operation, such as large agricultural products supermarket has become a new and major forms of modern agricultural products circulation. Agricultural products marketing intermediary development active. The main body of the purchase and sale of various agricultural products, such as self-employed, specialized households, the Commonwealth continues to grow and develop, these intermediary organizations, making the farmers a small-scale production and large market to achieve a docking, changing the past sales of the embarrassing situation, effectively alleviate the agricultural products Difficult to sell the problem.

\section{The Main Problems in the Marketing of Agricultural Products in China}

The concept of marketing is weak. As farmers by their own quality and capital, technology, information and other conditions, so that it can not effectively carry out agricultural marketing, but did not establish a large agricultural market integration marketing concept.

Marketing information is closed. China's existing rural information work is very weak foundation, the lack of independent control of information sources and marketing channels, agricultural production can not target different markets at home and abroad to achieve targeted 
sales.

The Application of Lack of Marketing Strategy in Agricultural Production. First, the lack of market segmentation and market positioning. Specific agricultural products sales target market is not clear; the second is the lack of product segmentation; third is the lack of pricing strategy; four is the lack of brand awareness.

Marketing team specialization and marketing organization of a lower degree. The current agricultural marketing is also limited to individual subjective judgment-oriented low-level marketing operations, can not accurately grasp the domestic and international market demand trend, can not achieve the agricultural industrialization of the overall operation of economies of scale requirements. Government marketing support is not enough. In recent years, although the government has introduced a lot of agricultural production in the promotion of agricultural production and development of preferential policies, but the agricultural products in the international market promotion is also not enough strength.

The agglomeration of agricultural products market is not mature. The current agricultural market intermediary organizations tend to put their own interests first, do not pay attention to the interests of farmers, seriously dampen the enthusiasm of farmers, resulting in farmers do not want to join the intermediary organizations. At the same time, the intermediary organizations failed to effectively link the processing, storage, transportation and other aspects of agricultural products, so that farmers and the market is not close enough.

\section{Essential Elements of Agricultural Marketing}

Agricultural base. Safe, high-quality, distinctive agricultural base construction is the basis of marketing, only the establishment of a stable base in order to cultivate a solid market, otherwise the marketing has become a passive water. Base construction can not only solve the agricultural leading enterprises "without rice" of the troubled, but also for the "company plus base" to lay a solid foundation for sustainable development. In the base construction to pay special attention to highlight the safety, quality and characteristics, the development of pollution-free, green and organic food base, and international standards.

Agricultural marketing team. The marketing team of agricultural products is the most active factor in the marketing of agricultural products. Training to create a number of domestic and foreign markets to develop the marketing team of agricultural products to improve their organizational level, give full play to their subjective initiative and creativity, can promote the development of agricultural marketing. Agricultural marketing team is to strengthen training, so that they establish a modern marketing concept, with modern marketing organization and marketing spirit, to carry out innovative agricultural marketing.

Agricultural Products Industry Association. Industry associations are members of the voluntary participation of cross-sectoral cross-ownership of non-profit, self-discipline industry organizations, is an independent economic society. The Association of Agricultural Products Industry is both the assistant of the government and the representative of the legitimate interests of the agricultural enterprises. Through the bridge link of the association, the agricultural marketing channel can be unimpeded to realize the win-win situation of the government, enterprises and farmers in the marketing of agricultural products.

Market positioning. Different regions of the agricultural market has different characteristics, different regions of the residents also have different spending habits. Agricultural marketing must accurately grasp the pulse of the market, in accordance with the requirements of the target marketing, the market segmentation positioning, so targeted. With the rapid economic development, market demand is constantly changing, to timely through market research and timely understanding of consumer demand changes in the market segment, the rapid adjustment of market positioning, to provide the best product portfolio.

Agricultural products brand. The brand management of agricultural products has just started in our country. It is necessary to realize the promotion effect, profit effect, competitive effect and expansion effect of agricultural products brand, and try to change the status quo of the development 
of agricultural brand. Now the developed countries of agricultural products is first-class products, first-class brand, first-class prices, and our country's agricultural products are first-class products, third-rate brand, third-rate price, profit margins can be imagined. We should strive to enhance the awareness of agricultural products brand, increase brand awareness. In addition to the publicity of enterprises and farmers themselves, local governments should actively do a good job in the promotion of agricultural products, expand visibility, improve market share, give full play to the role of the brand.

Product marketing network. It is necessary to establish a marketing network of agricultural products, such as wholesale markets, distribution centers, fresh supermarkets, but also to adapt to the new situation, the establishment of an intangible market network. Follow the rapid development of the network economy in the new form, and actively develop online marketing of agricultural products, build online marketing platform, the implementation of e-commerce, and strive to promote agricultural products more out of the country, so that China's agricultural products in the world market occupies more and more share.

\section{Marketing strategy for agricultural products}

From all aspects of efforts to change the agricultural funds and investment situation. As the market economy system gradually established for many investors to provide more opportunities for the realization of the interests of the pursuit of high returns and interests, investors are reluctant to invest as a weak industry, the amount of investment, Pay the longer period, the higher risk of agriculture, which led to the lack of investment in agriculture, lack of financial support for agricultural operations, so the government should proceed from the following three aspects.

In the market economy conditions, the pursuit of the quality of agricultural products, but also enterprises and farmers spontaneous pursuit. Improve the quality of agricultural products, first through the improved technology and other appropriate technology to obtain quality products; and then through the processing of agricultural products, packaging and other technologies to further improve the quality of agricultural products. In addition, the continuous renovation of technology, continuous development, making the growing variety of agricultural products, is conducive to the realization of product diversification. With the development of society, science and technology will become the core of agricultural competition, the government should actively introduce foreign advanced technology, the use of foreign resources, a set of China's current agricultural structure adjustment, accelerate the domestic agricultural products, scientific and technological content, improve product quality.

Agricultural information construction is a high-tech, high-input social welfare projects. In the early stages of the development of information technology, if there is no government financial support, rely on the service is difficult to maintain. Therefore, from the state of agricultural infrastructure investment the financial support and other funds in the appropriate arrangements for a certain share, the establishment of special funds, specifically for agricultural information construction. Involving the development of agricultural information related departments of the development fund, but also to the agricultural information projects tilt. The state should encourage and mobilize social forces to participate in the construction of rural information, improve the diversified investment mechanism, financing channels. Active and joint information industry, communication management and other relevant departments, enterprises and other social forces, multi-channel to increase investment in agricultural information construction, the establishment of government investment-led, social capital investment as the main body, universities, agricultural enterprises, agricultural professional associations And research institutes and other units to participate in a diversified investment pattern, thereby strengthening the information services. In the market economy, the country's macro-control mainly rely on economic, legal and other means. At the same time, the establishment of agricultural products standardization and security system also requires legal protection; the improvement and implementation of market supervision and regulations need more legal basis.

Most producers of agricultural products pay more attention to the production of agricultural 
products than to the sale of agricultural products, pay more attention to the number of agricultural products rather than the quality of agricultural marketing awareness is relatively weak. With the development of society, the establishment of market economic system, people gradually began to change some of the old ideas, and slowly began to pay attention to product quality and market demand. Although there has been some progress compared to the previous, but the agricultural producers on the market demand for consumers did not conduct in-depth analysis, of course, did not make the consumer's needs are fully satisfied. Therefore, the agricultural products in order to achieve satisfactory business results, it should establish a consumer demand as the center of the modern marketing concept.

Product strategy includes new product strategy, product mix strategy, packaging strategy and brand strategy. For new products, agricultural producers should choose their own products under the conditions of the development and production of new products, while focusing on the development of green agricultural products to meet the multi-level needs; product mix is the farmer or business for their own product line design and development to meet Modern urban residents of the multi-level needs, and to overcome the fresh agricultural products should not be stored, transport and preservation of the shortcomings, while the processed products can not be seasonal and geographical restrictions, sales radius increases; modern marketing, packaging The role is not only to protect the product and easy to transport, but as a means of marketing, fine packaging is often more attractive to people to buy products; the establishment of agricultural products brand is the market economy under the conditions of competition, scientific and effective brand building for The growth of agricultural products is of great significance. The agricultural products with good brand image are the products with high quality, high purchasing power, good market share and remarkable economic benefits in the agricultural industry. It is a symbol of the quality of agriculture and agricultural products in China.

\section{Conclusion}

Strengthen the marketing of agricultural products, to promote the agricultural market demand, and effectively increase the income of farmers, is of great significance. Based on the basic principles of marketing, this paper analyzes the current situation of marketing of agricultural products, combined with the basic elements of marketing of agricultural products, and makes a deep thinking on the marketing of agricultural products in order to play the role of marketing in solving the problems of "agriculture, countryside and farmers" effect.

\section{References}

[1] Zheng Shujuan. Malaysian durian products allowed to export to the Chinese market [J]. World Tropical Agriculture Information, 2016 (07)

[2] Zhang Zhaofeng. The county agricultural products marketing status and development trend of [J]. Time Finance, 2014 (05)

[3] Du Xiaofeng, Xu Min. China's agricultural product marketing development status and innovative way [J]. Modern business, 2014 (12)

[4] Dai Yongxiu, Dai Yongwen, Fu Zunbin. Talking about the marketing of agricultural products [J]. Science and Technology Forum (the second half), 2010 (10)

[5] Wang Ning. China's agricultural products marketing status and innovation [J]. Modern agriculture, 2009 (06)

[6] Jia Ming. Five measures to do a good job of agricultural marketing marketing [J]. Rural Finance Accounting, 2009 (11) 